\title{
A validated HPTLC method for quantification of cordifolioside $A$, 20- $\beta$-hydroxyecdysone and columbin with HPTLC-ESI-MS/MS characterization in stems of Tinospora cordifolia
}

\author{
Urvi Patel $^{1} \cdot$ Aboli Girme $^{2} \cdot$ Kalpana Patel $^{1}$ (D) $\cdot$ Chetana Ghule $^{2} \cdot$ Lal Hingorani $^{2} \cdot$ Tejal Gandhi $^{1}$
}

Received: 12 March 2021 / Accepted: 14 July 2021 / Published online: 11 August 2021

(c) Akadémiai Kiadó, Budapest, Hungary 2021

\begin{abstract}
The objective of the present work was to develop a simple, specific, and fast high-performance thin-layer chromatographic (HPTLC) method to identify and quantify cordifolioside A, 20- $\beta$-hydroxyecdysone and columbin with HPTLC-electrospray ionization-tandem mass spectrometry (ESI-MS/MS) for characterization in Tinospora cordifolia stem extracts. Chromatographic development was performed using a HPTLC aluminum plate, pre-coated with silica gel $60 \mathrm{~F}_{254}$ with hexane-chloroform-methanol-formic acid as the mobile phase. Densitometric quantification for $20-\beta$-hydroxyecdysone and cordifolioside A was performed at $254 \mathrm{~nm}$ and for columbin at $600 \mathrm{~nm}$ after derivatization with anisaldehyde-sulfuric acid. The optimized mobile phase resulted in chromatographic separation of peaks for cordifolioside A, 20- $\beta$-hydroxyecdysone, and columbin at $R_{\mathrm{F}}$ of $0.12,0.47$, and 0.86 , respectively. The linear concentration range was found to be $750-2250 \mathrm{ng} / \mathrm{band}$ for $20-\beta$-hydroxyecdysone and cordifolioside A and 675-1875 ng/band for columbin with $\left(r^{2}>0.99\right)$. The methodology showed good recoveries as $98.96-101.43 \%$ for cordifolioside A, $98.15-101.56 \%$ for $20-\beta$-hydroxyecdysone, and $98.06-98.80 \%$ for columbin. The limit of detection was found for columbin, 20- $\beta$-hydroxyecdysone, and cordifolioside A as $53.86 \mathrm{ng} / \mathrm{band}$, $40.90 \mathrm{ng} / \mathrm{band}$, and $107.05 \mathrm{ng} / \mathrm{band}$, while the limit of quantification was found to be $163.21 \mathrm{ng} / \mathrm{band}, 123.94 \mathrm{ng} / \mathrm{band}$, and $324.38 \mathrm{ng} / \mathrm{band}$, respectively. The relative standard deviation for precision and robustness study for all the markers was found to be within $2 \%$. Three markers were identified and confirmed in $T$. cordifolia stem extracts by ESI-MS/MS. Compounds were assigned as norditerpene furan glycosides, ecdysteroids, and diterpenoid furanolactone: cordifolioside A $(\mathrm{m} / z=527$ $\left.[\mathrm{M}+\mathrm{Na}]^{+} ; \mathrm{UV} \lambda_{\max } 221 \mathrm{~nm}\right), 20-\beta$-hydroxyecdysone $\left(\mathrm{m} / z=481.30[\mathrm{M}+\mathrm{H}]^{+} ; \mathrm{UV} \lambda_{\max } 247 \mathrm{~nm}\right)$, and columbin $(\mathrm{m} / z=359$ $[\mathrm{M}+\mathrm{H}]^{+} ; \mathrm{UV} \lambda_{\max } 210 \mathrm{~nm}$ ). The optimized method was found accurate, reproducible, robust, and specific and can be applied for the quantification of cordifolioside A, 20- $\beta$-hydroxyecdysone, and columbin for quality control of extracts of $T$. cordifolia.
\end{abstract}

Keywords High-performance thin-layer chromatography (HPTLC) · Tinospora cordifolia $\cdot$ Guduchi $\cdot$ Giloy $\cdot$ Amrita $\cdot$ Immunomodulatory

\section{Introduction}

The regulatory requirements of the World Health Organization (WHO) emphasized proving the scientific validity of nutraceuticals or botanical drugs based on the application of sound scientific knowledge, thereby ensuring the identity, purity, and quality of herbal drugs [1-3]. The wide

Kalpana Patel

kalpana_jpatel@yahoo.com

1 Pharmacology Department, Anand Pharmacy College, Anand, India

2 Pharmanza Herbal Pvt. Ltd., Anand, Gujarat 388435, India popularity of herbals or botanicals is due to their easy availability and patient acceptability. But the heterogeneous nature of the botanical drugs along with their complexity in terms of varied active constituents is critical for ensuring their therapeutic efficacy. For this, standardization is essential as it is a valuable tool for identifying and quantifying various chemical constituents of botanicals and drugs, thereby also differentiating related species [4]. Marker-based standardization is one of the important methods of characterization of botanical drugs. Standardization also aids in defining the amount of constituents that are attributable to biological activity [5, 6]. Additional measures for quality include botanical raw material control, quality control by chemical 
test and analytical test, biological assay along with supporting clinical data.

Tinospora cordifolia, belonging to the Menispermaceae family, is widely used in the indigenous system of medicine [5]. T. cordifolia family is widely distributed throughout the tropical India subcontinent, Sri Lanka, and China, ascending to $1200 \mathrm{~m}$. T. cordifolia is also known as Amrita (Guduchi) in Sanskrit; 'Giloy' in Hindi and is widely used in the Ayurvedic system of medicine "Rasayanas" for strengthening the immune system and improving the body resistance against infections [7]. The stem is succulent with long fili form fleshy aerial roots, and the bark is creamy white to grey.

Many research communications report the scientific evaluation of efficacy of $T$. cordifolia. The immunomodulatory activity of the plant is very well-known in traditional and modern science. Moreover, it has a wide variety of other uses, including the treatment of general weakness, fever, dyspepsia, dysentery, gonorrhea, urinary diseases, viral hepatitis, anemia, antineoplastic, hypoglycemic, anti-inflammatory, and antioxidant activities $[8,9]$. In previous clinical trials, the water extract of $T$. cordifolia stem was found to be effective for allergic rhinitis, immunomodulation in HIV positive patients, and burn patients [10-13].

T. cordifolia plant mainly reveals the presence of terpenoids, alkaloids, lignan, carbohydrates, bitters, steroids, glycosides, and sesquiterpenoids, aliphatic compounds, essential oils, fatty acids, and polysaccharides [14]. The aerial parts, mainly stems of $T$. cordifolia, various constituents including phenyl propanoid glycosides like cordifolioside A and $\mathrm{B}$, syringin with diterpenoids tinosporaside, tinosporin, tinosporidine, tinocordifolioside, and alkaloids columbin, isocolumbin, berberine, magnoflorine have been reported [14-16]. These chemical constituents possess different therapeutic activities.

The chemical and biological marker compounds from stems of $T$. cordifolia have shown a promising role in immunomodulatory and protective properties. Cordifolioside A, a glycoside from phenyl propanoid class from T. cordifolia, showed immunostimulant with cardio and radioprotective activities. At the same time, a phytosterol 20- $\beta$-hydroxyecdysone has been studied in a large number of studies with many potential beneficial health effects, including the immunoprotective wound-healing and anti-osteoporosis effects [17-23]. It has also been studied as an alternative therapeutic option for the prevention and alleviation of cardiometabolic syndrome. The study reveals its anti-inflammatory, anti-fibrotic, and cardioprotective role in the restoration of renin-angiotensin system balance and improves the health of COVID-19 patients who have severe pneumonia [24]. Columbin is a diterpenoid furanolactone; it displays anti-inflammatory, anti-cancer, and antioxidant activity, protects from azoxymethane-induced rat colon carcinogenesis and possess a trypanocidal mechanism $[25,26]$. Hence, $T$. cordifolia has been drawn interest in research as a COVID-19 preventive measure [27, 28].

Due to widespread use, chromatographic standardization of T. cordifolia is an important aspect for assuring quality, safety, and efficacy [29]. Chromatographic fingerprinting is the most widely used method for controlling the quality of botanical drugs and extracts using techniques such as thin-layer chromatography (TLC), high-performance thinlayer chromatography (HPTLC), high-performance liquid chromatography (HPLC), and other hyphenated techniques, TLC-mass spectrometry (MS), HPLC-MS. Among these, HPLC and HPTLC are used routinely for the analysis of nutraceuticals and botanicals. In comparison, HPTLC-MS/ MS, LC-MS or LC-MS/MS are analytical techniques that enable rapid identification with higher specificity analyzing complex herbal samples [30]. Moreover, the applicability of LC-MS in herbal samples includes the various characteristics; mobile phase selection, stationary phase, high resolution, accurate mass measurements, selectivity and fragmentation behavior along with characterization of structure. LC-MS as a powerful tool is used for analyzing multicomponents that are present in complex herbal matrix [31].

Some of the analytical methods have been reported in the literature for Tinospora plants [32-45]. The literature reports some of the HPLC methods for study of morphoanatomies of leaves and stems of Tinospora species. The presence of 20- $\beta$-hydroxyecdysone, tinosporaside, cordiside, and columbin has been confirmed in various species by HPLC method. HPTLC method for determination of different markers like tinosporaside, berberine has been reported. However, still, a validated and specific markerbased HPTLC method using markers like cordifolioside A, $20-\beta$-hydroxyecdysone, and columbin is lacking and is desirable for the quality control of Tinospora species. Hence, the present research is the first one that describes the development and validation of the HPTLC-densitometry (DS) method for standardization and simultaneous quantification of columbin, 20- $\beta$-hydroxyecdysone, and cordifolioside A with confirmation by HPTLC-MS/MS data in T. cordifolia. Thus, the objective of this research study was to develop and optimize cordifolioside A, 20- $\beta$-hydroxyecdysone, and columbin (Fig. 1) in extracts of $T$. cordifolia followed by validation of methodology as per International Council for Harmonisation (ICH) guidelines for linearity, accuracy, precision with a limit of detection (LOD), limit of quantification (LOQ). This methodology will be useful for qualitative fingerprinting and quantitative marker-based standardization by HPTLC for extracts of stem of $T$. cordifolia. Moreover, characterization of cordifolioside A, 20- $\beta$-hydroxyecdysone, and columbin in the stem extracts of $T$. cordifolia can be confirmed by triple quadrupole (TQ)-electrospray ionization (ESI)-MS. 
<smiles>COc1cc(/C=C/CO)cc(OC)c1OC1OC(CO)C(O)[C@H](OC2OC[C@@H](CO)[C@H]2O)[C@H]1O</smiles>

Cordifolioside A (1)<smiles>CC(C)(O)CCC(O)C(C)(O)C1(C)CCC2(O)C3CC(=O)C4CC(O)C(O)CC4(C)C3CCC21C</smiles>

$20 \beta$-hydroxy ecdysone (2)

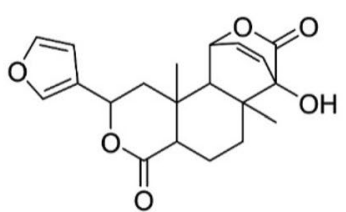

Columbin (3)

Fig. 1 The chemical structures of marker compounds from Tinospora cordifolia. (1) cordifolioside A; (2) 20- $\beta$-hydroxyecdysone, and (3) columbin

\section{Experimental}

\subsection{Materials}

T. cordifolia plant was collected from Ratnagiri (Maharashtra, India). The voucher specimen was submitted and authenticated by the Botanical Survey of India, Jodhpur, India.

The markers, cordifolioside A, 20- $\beta$-hydroxyecdysone, and columbin, were isolated in-house from dried and powdered stems of $T$. cordifolia by reported methodologies. All the isolated compounds were identified and characterized using ultraviolet (UV), Fourier-transform infrared spectroscopy (FTIR), HPLC-photodiode array (PDA), MS, and nuclear magnetic resonance (NMR) [23, 46, 47]. The minimum purity of the compounds was confirmed by analysis of HPLC in $1 \mathrm{mg} / \mathrm{mL}$ concentration in isocratic elution, and it was found to be greater than $90 \%$. All chemicals and reagents used in the study were of analytical grade and purchased from Merck Specialities Pvt. Ltd. (Mumbai, India).

The dried and powdered stems of $T$. cordifolia $(1 \mathrm{~kg})$ were refluxed with $4 \mathrm{~L}$ water and water-ethanol $(1: 1, V / V)$ under stirring at $60 \pm 5{ }^{\circ} \mathrm{C}$ for $3 \mathrm{~h}$, and the filtrate was collected. The process was repeated two more times, and the obtained filtrate was dried under vacuum to get powdered extract (yields: $100 \mathrm{~g}$ and $123 \mathrm{~g}$ ) for aqueous and hydroalcoholic extract.

\subsection{Instrumentation and software}

A CAMAG HPTLC system (Muttenz, Switzerland) comprising of a CAMAG Linomat $\mathrm{V}$ semi-automatic sample applicator, CAMAG TLC Scanner IV, CAMAG TLC visualizer, flat bottom and twin-trough developing chamber $(10 \times 10 \mathrm{~cm})$, UV cabinet with dual-wavelength UV lamp, Hamilton syringe (100 $\mu \mathrm{L}$; Bonaduz, Switzerland), ultrasonic bath (Frontline FS-4, Mumbai, India) and CAMAG winCATS software was used in the study. Calculations were performed by the use of Microsoft Excel 2007 software for linear regression analysis for quantification of extracts and determination of validation parameters, accuracy, precision, robustness. Bartlett's test was also performed for determining homoscedasticity of variance for data of linearity in MS Excel 2007.

\subsection{Instrumental and chromatographic conditions}

The samples were spotted in the form of bands having a band width of $8 \mathrm{~mm}$ with a $100-\mu \mathrm{L}$ microsyringe (Linomat syringe 659.0014) on pre-coated silica gel aluminum HPTLC plate $60 \mathrm{~F}_{254}(10 \mathrm{~cm} \times 10 \mathrm{~cm}, 100 \mu \mathrm{m}$ thickness, E. Merck, Darmstadt, Germany) using a CAMAG Linomat $\mathrm{V}$ sample applicator. Then, the plates were dried with a cold air dryer. Densitometric scanning was done in absorbance-reflectance mode at $254 \mathrm{~nm}$ using a deuterium lamp and $600 \mathrm{~nm}$ using a halogen tungsten lamp. The slit dimensions were set at $0.60 \mathrm{~mm} \times 0.45 \mathrm{~mm}$, the scanning speed at $20 \mathrm{~mm} / \mathrm{s}$, and the data resolution at $100 \mu \mathrm{m} / \mathrm{step}$. The results were evaluated to achieve an optimum separation between spots and migration of spots to ensure separation reproducibility.

\subsection{Preparation of standard solutions of cordifolioside $A, 20-\beta$-hydroxyecdysone, and columbin}

Accurately weighed $3.0 \mathrm{mg}$ of each analyte (cordifolioside A, 20- $\beta$-hydroxyecdysone, and columbin) individually was transferred into an $5 \mathrm{~mL}$ Eppendorf tube, dissolved in $2 \mathrm{~mL}$ of methanol, and mixed well. This solution was used for qualitative analysis. For validation, an aliquot of $5.0 \mathrm{mg}$ of each marker was dissolved in $5 \mathrm{~mL}$ of volumetric flask for preparation of stock solution with a concentration of $1000 \mu \mathrm{g} / \mathrm{mL}$ for each standard marker in volumetric flask. From the stock solutions, the working standard solution was prepared to have a concentration of $375 \mu \mathrm{g} / \mathrm{mL}$ of each marker. These stock and working standard solutions were stored at $4-6{ }^{\circ} \mathrm{C}$. 


\subsection{Mobile phase optimization}

The mobile phase was optimized for TLC using solvents of different polarities, consisting of chloroform, methanol, toluene, hexane, ethyl acetate in different proportions and combinations with saturation of chamber for $10 \mathrm{~min}$. Working standard solutions were applied to the HPTLC plates as $8 \mathrm{~mm}$ bands using Linomat 5. Prior to use, the mobile phase components were mixed. Before each run, the development chamber was allowed to saturate with mobile phase vapor for $10 \mathrm{~min}$.

\subsection{HPTLC fingerprinting}

An aqueous and hydroalcoholic extract of stems of T. cordifolia was applied on TLC plate, and the plate was developed in optimized mobile phase and further dried at room temperature in air. The plate was scanned at $254 \mathrm{~nm}$ before spraying and at $600 \mathrm{~nm}$ after spraying with detection reagent (anisaldehyde-sulfuric acid reagent), and the plate was heated at $110^{\circ} \mathrm{C}$ for $5 \mathrm{~min}$. The retardation factor $\left(R_{\mathrm{F}}\right)$ values and color of the resolved bands were noted.

\subsection{Method validation}

The method was validated as per ICH guidelines Q2 (R1) for the determination of validation parameters; linearity, precision, accuracy, LOD and LOQ, and robustness [48, 49]. The linear relationship between peak area and concentration of all three markers was evaluated by regression coefficient over the concentration range of 750-2250 ng/band for 20- $\beta$-hydroxyecdysone and cordifolioside A (at $254 \mathrm{~nm}$ before derivatization) and 675-1875 ng/band for columbin (at $600 \mathrm{~nm}$ after derivatization) by making five replicate measurements using different calibration sets. The standard deviations of slope and the intercept were calculated using ordinary least squares. Further linearity was verified by Bartlett's test for confirming homoscedasticity of variance. The precision of the developed method was evaluated by performing repeatability and intermediate precision studies, and the peak area measured was expressed in terms of percent relative standard deviation (\%RSD). The sample application's repeatability was evaluated by applying the same concentration six times and further scanning and accumulating results as $\% R S D$. The intra-day precision study was carried out by performing three replicates of three different concentrations $(750,1500$, and $2250 \mathrm{ng} / \mathrm{band}$ for 20- $\beta$-hydroxyecdysone and cordifolioside A; 675, 1275, and $1875 \mathrm{ng} / \mathrm{band}$ for columbin) on the same day. Similarly, an intermediate precision study was performed on different days.

The accuracy was assessed by the methodological recovery studies to check the recovery at different levels: $80 \%$,
$100 \%$, and $120 \%$ by adding a known amount of standard to the extracts and analyzed by the proposed method, in triplicate. As per the ICH guideline, the LOD and LOQ were computed from the standard deviation of the response, peak area and slope of the calibration curve of markers using the formulas $\mathrm{LOD}=3.3 \times \sigma / S$ and $\mathrm{LOQ}=10 \times \sigma / S$, where $\sigma$ is the standard deviation of response, peak area, $S$ is the slope of the calibration curve. The specificity of the method was ascertained by analyzing the standard marker and extracts. The band for cordifolioside A, 20- $\beta$-hydroxyecdysone, and columbin in extract was confirmed by comparing the $R_{\mathrm{F}}$ and spectra of the band with those of standard and further, peak purity index was assessed by comparing the spectra at three different levels, i.e., peak start $(S)$, peak apex $(M)$, and peak end $(E)$ positions of the band. The robustness of the proposed HPTLC method was evaluated on the response, $R_{\mathrm{F}}$, and peak area by small changes in different method conditions: mobile phase ratio $( \pm 0.1 \mathrm{~mL}$ in the volume of methanol); saturation time $( \pm 0.5 \mathrm{~min})$; solvent front $(85 \pm 2 \mathrm{~mm})$; wavelength change $(254 \pm 2 \mathrm{~nm})$ and $(600 \pm 2 \mathrm{~nm})$.

\subsection{Fingerprinting and analysis of the $T$. cordifolia extracts}

From the T. cordifolia extracts, an aliquot of $100 \mathrm{mg}$ of each was accurately weighed and transferred into a volumetric flask, dissolved in $2 \mathrm{~mL}$ water, and sonicated further for $10 \mathrm{~min}$. The solution was then filtered through Whatman filter paper. After preparation as previously described, the sample solution ( $4 \mu \mathrm{L}$ ) was spotted on a plate, developed under the same conditions as described for the standard. After the development and drying of the plates, all three markers were found to be completely separated. The bands at the respective $R_{\mathrm{F}}$ value were scanned for detecting the peak of cordifolioside A, 20- $\beta$-hydroxyecdysone at $254 \mathrm{~nm}$, and after derivatization with anisaldehyde-sulfuric acid for columbin at $600 \mathrm{~nm}$, and the concentration of each marker in the extract was determined from the calibration curve plotted by linear regression analysis.

\subsection{Extraction and characterization of markers by TLC-MS interface}

The targeted analytes cordifolioside A, 20- $\beta$-hydroxyecdysone have been eluted by TLC-MS interface based on $R_{\mathrm{F}}$ values of the standard before derivatization, whereas columbin was observed and eluted after derivatization. The bands of markers were eluted with methanol by using TLCMS interface 2 (CAMAG) and analysis with the help of ESI detector by using the LC-MS 8045 (Shimadzu, Kyoto, Japan) controlled by LabSolutions software, with mobile phase A: $0.1 \%$ formic acid in water and B: acetonitrile, flow rate $(1.0 \mathrm{~mL} / \mathrm{min})$, nebulising gas flow $(1.5 \mathrm{~L} / \mathrm{min})$, 
desolvation line (DL) temperature $\left(250{ }^{\circ} \mathrm{C}\right)$, and detector voltage $(0.95 \mathrm{kV})$. The mass spectrum was recorded at positive and negative ion mode using ESI source [50, 51].

\section{Results and discussion}

\subsection{Optimization of detection wavelength and mobile phase}

Spectra of the cordifolioside A, 20- $\beta$-hydroxyecdysone, and columbin were recorded in the wavelength range of 200 to $700 \mathrm{~nm}$ using the scanner, where cordifolioside A showed maximum intensity at $240 \mathrm{~nm}, 20$ - $\beta$-hydroxyecdysone at $254 \mathrm{~nm}$. Columbin gave lower intensity at $210 \mathrm{~nm}$ (before derivatization), while columbin gave high intensity after derivatization with anisaldehyde-sulfuric acid at $600 \mathrm{~nm}$. Hence, the detection wavelength for two markers, cordifolioside A and 20- $\beta$-hydroxyecdysone, for validation, was selected as $254 \mathrm{~nm}$ before derivatization, and for columbin, detection was performed after derivatization at $600 \mathrm{~nm}$ (Fig. S1).

Mobile phase optimization using trial and approach method was performed for separation of marker compounds bands (cordifolioside A, 20- $\beta$-hydroxyecdysone and columbin). The initial mobile phase composition of chloroform and methanol in the ratio of $6: 4(V / V)$ was unable to achieve adequate separation. Further, modification of mobile phase composition with addition of toluene showed separation of marker compound with broad band. Hence, toluene was replaced by hexane and formic acid as modifier was added for better separation of bands. Hexane-chloroform-methanol-formic acid (4:4:2:0.1\%, $V / V)$ as optimized mobile phase resulted in a good separation of bands at $R_{\mathrm{F}}$ of 0.12 , 0.47 , and 0.86 for cordifolioside A, 20- $\beta$-hydroxyecdysone and columbin, respectively (Fig. S2).

\subsection{HPTLC fingerprinting}

HPTLC fingerprint development showed dark brown band, greenish blue band at $254 \mathrm{~nm}$ for cordifolioside $\mathrm{A}\left(R_{\mathrm{F}} 0.12\right)$, 20 - $\beta$-hydroxyecdysone $\left(R_{\mathrm{F}} 0.43\right)$, whereas bluish violet band for columbin $\left(R_{\mathrm{F}} 0.85\right)$ in white light after derivatization with anisaldehyde-sulfuric acid was observed in aqueous and hydroalcoholic extract of stems of T. cordifolia. HPTLC fingerprint was developed for identification of marker compounds band in aqueous and hydroalcoholic extract in comparison with reference standard band (Fig. 2).

\subsection{Method validation}

The method was validated in accordance with ICH guidelines Q2 (R1) by determination of validation parameters. The linearity of the calibration curve was established by
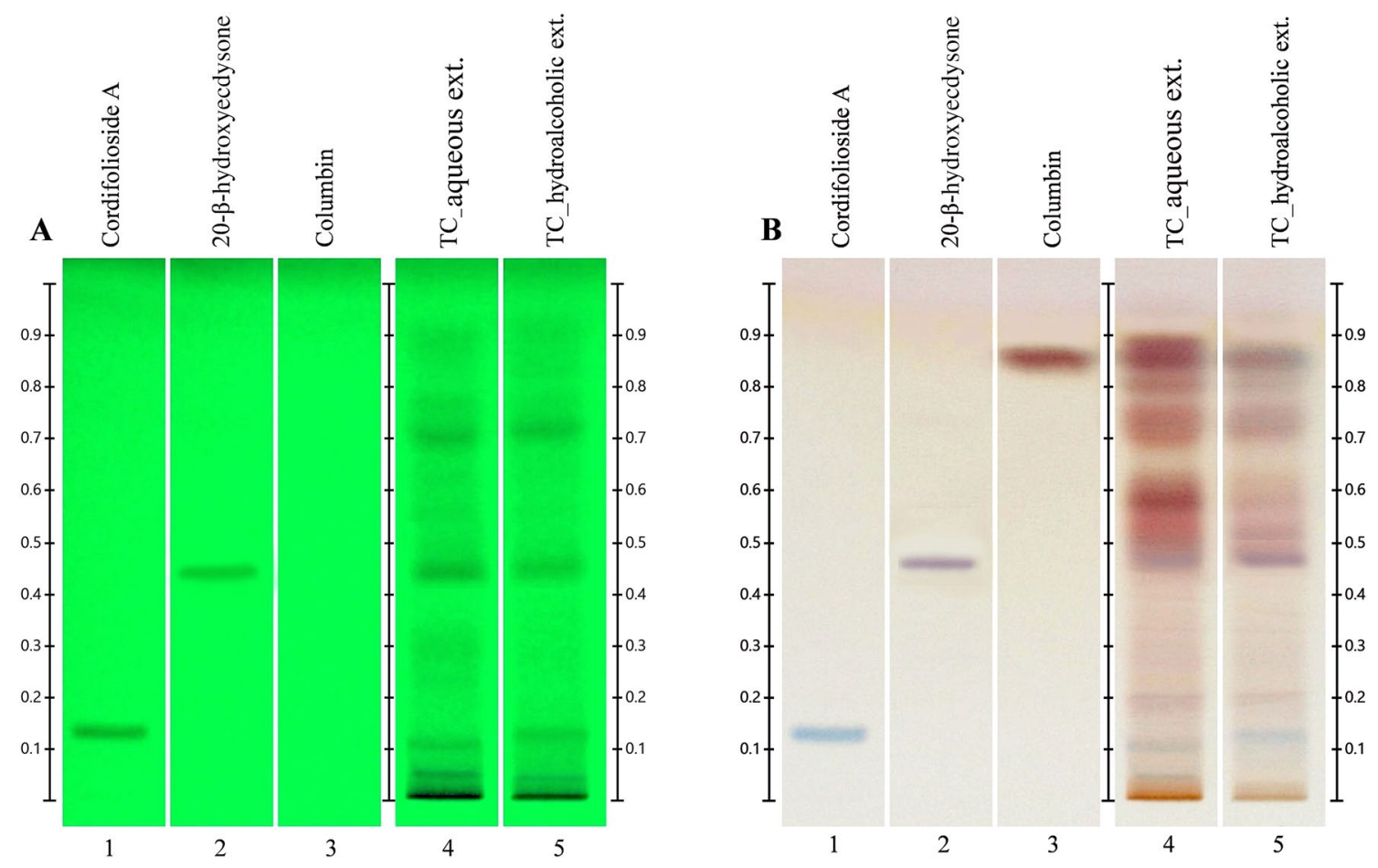

Fig. 2 Developed HPTLC plate photograph of water and hydroalcoholic extracts of T. cordifolia stem with marker compounds. A 254 nm before derivatization. B Visible mode after derivatization 
a high correlation coefficient and residuals measured for different calibration sets (Figs. 3, 4). Further linearity was verified by Bartlett's test confirming homoscedasticity of variance that was exemplified by Chi-square value less than tabulated value (9.488) (Table 1). As per ICH guidance, determination of LOD and LOQ was performed on standard deviation of the response, peak area measured for five different calibration sets. LOD for columbin,
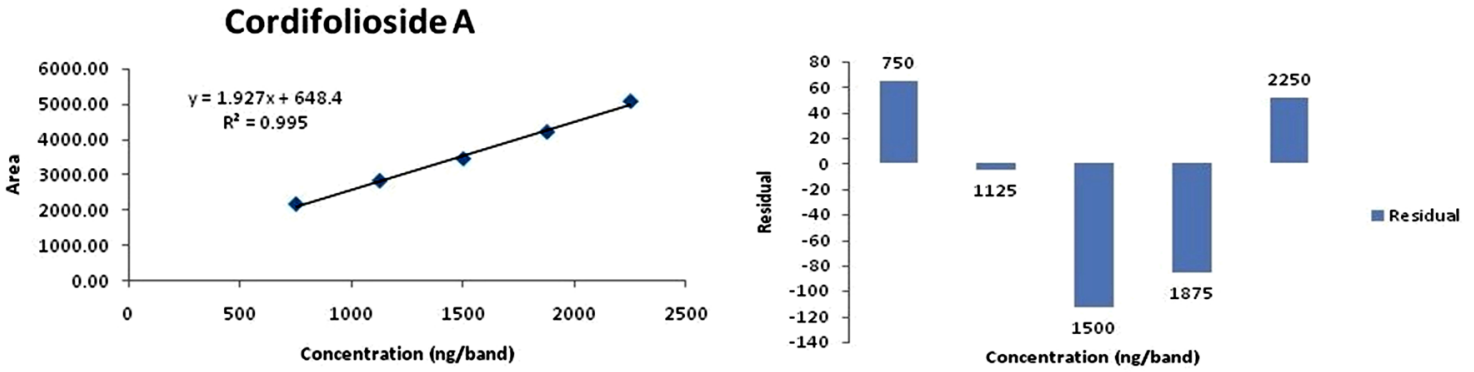

20- $\beta$-hydroxyecdysone
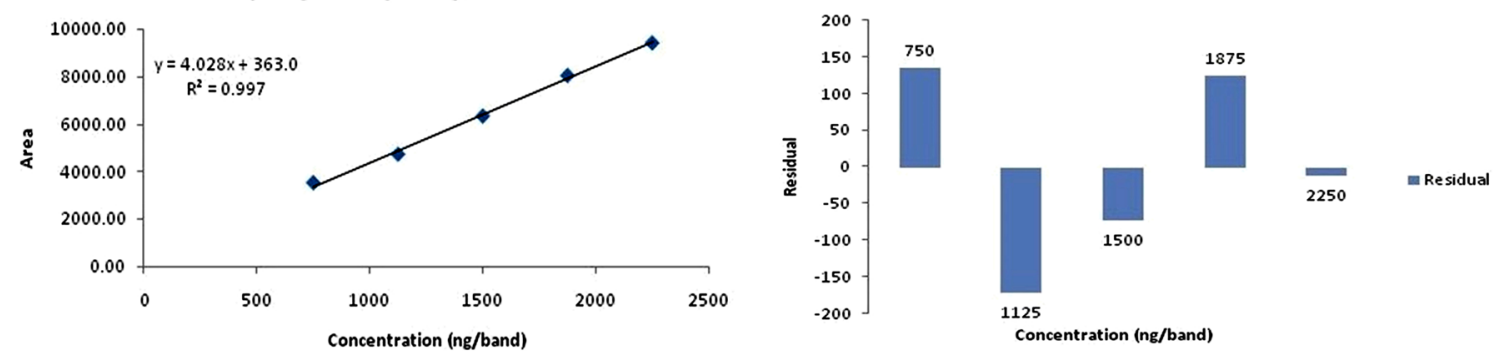

\section{Columbin}
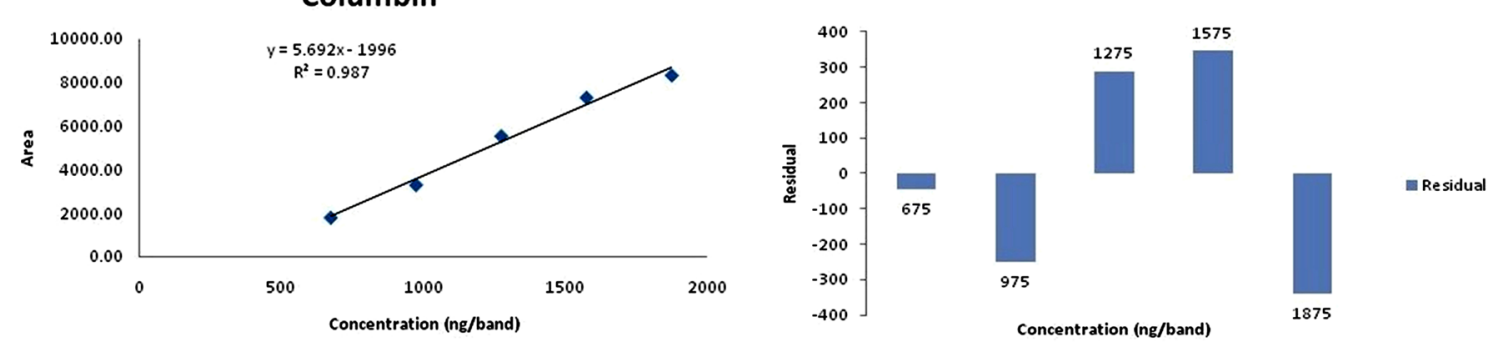

Fig. 3 Calibration plot and plot of residuals for cordifolioside A, 20- $\beta$-hydroxyecdysone and columbin in the linear calibration range
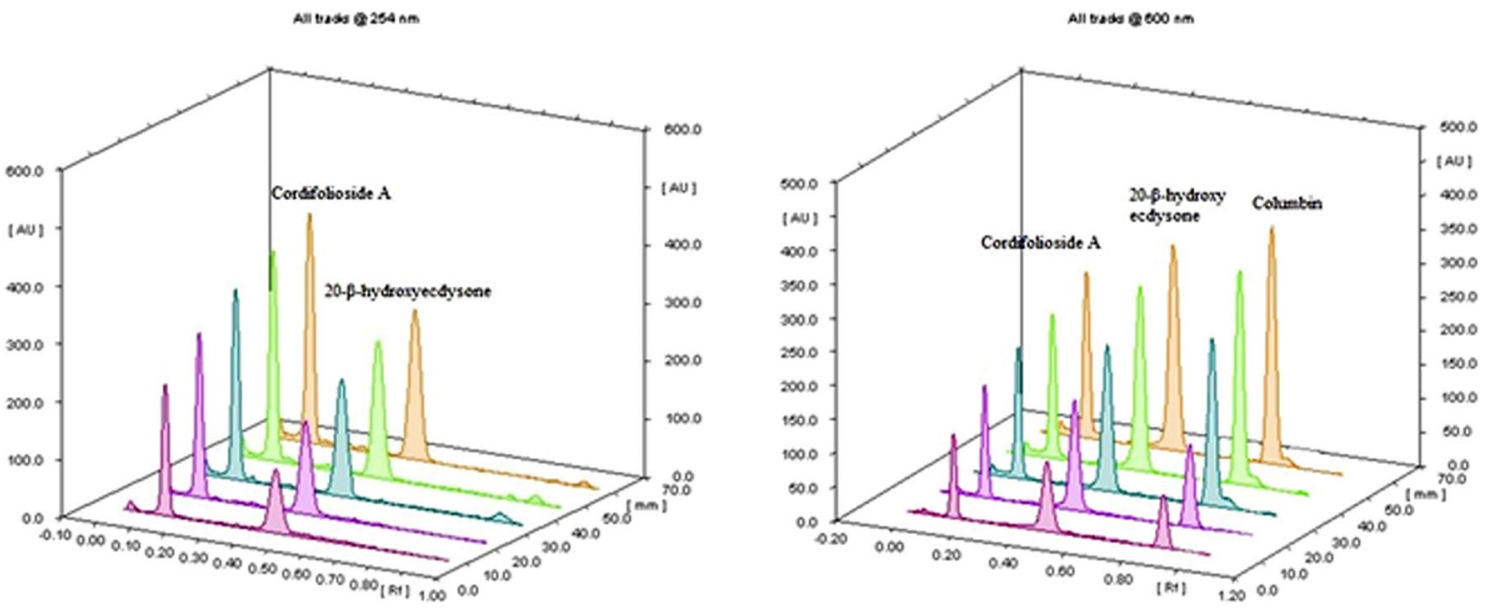

Fig. 4 Three-dimensional densitogram for linearity. A Cordifolioside A and 20- $\beta$-hydroxyecdysone at $254 \mathrm{~nm}$. B Columbin at $600 \mathrm{~nm}$ 
Table 1 Linear regression parameters for cordifolioside A, 20- $\beta$-hydroxyecdysone, and columbin in optimized DS based HPTLC studies

\begin{tabular}{|c|c|c|c|}
\hline Parameters & Cordifolioside A & 20 - $\beta$-hydroxyecdysone & Columbin \\
\hline Linearity $^{\mathrm{a}}$ (ng/band) & $750-2250$ & $750-2250$ & $675-1875$ \\
\hline Correlation coefficient $\left(R^{2}\right)$ & 0.995 & 0.997 & 0.987 \\
\hline Regression equation & $y=1.927 x+648.4$ & $y=4.028 x+363.0$ & $y=5.692 x+1996$ \\
\hline LOD (ng/band) & 107.05 & 40.90 & 53.86 \\
\hline LOQ (ng/band) & 324.38 & 123.94 & 163.21 \\
\hline Bartlett's test ${ }^{\mathrm{b}}\left(\chi^{2}\right)$ & 0.0266 & 0.0004 & 0.0039 \\
\hline
\end{tabular}

${ }^{\mathrm{a}}$ Mean of five replicates, five concentrations

${ }^{\mathrm{b}}$ Calculated value $\chi^{2}$ less than critical value $\chi^{2}(0.05,4)=9.488$
20 - $\beta$-hydroxyecdysone, and cordifolioside A was 53.86, 40.90 , and $107.05 \mathrm{ng} / \mathrm{band}$, while LOQ was found to be 163.21, 123.94, and $324.38 \mathrm{ng} / \mathrm{band}$ (Table 1). The precision study was repeated three times in a day (intra-day precision) and on three different days (inter-day precision) with the determination of the average \%RSD values for peak area of columbin, 20- $\beta$-hydroxyecdysone and cordifolioside A. Both intra-day and inter-day precision studies resulted in $\% R S D$ less than 2 , confirming that the method is reproducible (Table 2). Recovery studies were carried out by spiking three different amounts of 20- $\beta$-hydroxyecdysone, cordifolioside A, and columbin $(600,750$, and $900 \mathrm{ng} / \mathrm{band})$ to the extract $(750 \mathrm{ng} /$ band) by the standard addition method. Recoveries for the three markers were found to be $98.96-101.43 \%$ for cordifolioside A, $98.15-101.56 \%$ for $20-\beta$-hydroxyecdysone, 98.06-98.80\% for columbin (Table 3). The densitogram of the extract obtained using the developed method showed peaks at $R_{\mathrm{F}}$ of $0.12,0.47$, and 0.85 for cordifolioside A, 20 - $\beta$-hydroxyecdysone, and columbin, respectively, found to be at the $R_{\mathrm{F}}$ value similar to standard markers (Fig. 5).
The peak purity of all markers in this botanical extract, when evaluated by comparing the overlaid spectra at peak start, peak apex, and peak end positions of the spot, showed a peak purity of more than 0.99 for all markers (Fig. 6, Fig. S4 and Table S3). Small, deliberate changes in different parameters like mobile phase composition, chamber saturation time, distance traveled, wavelength showed less than $2 \%$ RSD for a response, peak area, and $R_{\mathrm{F}}$; the results reveal that there is only a slight effect on $R_{\mathrm{F}}$ and peak area, indicating that the method is robust (\%RSD between 0.05 to 1.45 ).

\subsection{Quantification of compounds (1-3) by HPTLC-DS in T. cordifolia extracts}

The content $(n=3, \mathrm{RSD}<5.0 \%)$ of cordifolioside A, $20-\beta$-hydroxyecdysone, and columbin was found to be 0.134 , 0.845 , and $0.196 \% w / w$ in hydroalcoholic extract and 0.017 , 0.499 , and $0.284 \% w / w$ in aqueous extract by the validated HPTLC-DS method (Fig. 5 and Table 4).
Table 2 Precision studies as repeatability and inter-day precision for the determination of cordifolioside A, 20 - $\beta$-hydroxyecdysone, and columbin by HPTLC-DS method

\begin{tabular}{|c|c|c|c|c|c|c|}
\hline \multirow[t]{3}{*}{ Amount (ng/band) } & \multirow{2}{*}{\multicolumn{2}{|c|}{ Repeatability }} & \multicolumn{4}{|c|}{ Inter-day precision } \\
\hline & & & \multicolumn{2}{|c|}{ Day 1} & \multicolumn{2}{|l|}{ Day 2} \\
\hline & Peak $_{\text {area }}{ }^{\mathrm{a}} \pm \mathrm{SD}$ & $\% R S D$ & Peak area ${ }^{\mathrm{a}} \pm \mathrm{SD}$ & $\% R S D$ & Peak area ${ }^{a} \pm S D$ & $\% R S D$ \\
\hline \multicolumn{7}{|l|}{ Columbin } \\
\hline 675 & $1833.9 \pm 28.8$ & 1.57 & $1865.2 \pm 15.2$ & 0.81 & $1858.7 \pm 34.0$ & 1.83 \\
\hline 1275 & $5596.0 \pm 54.4$ & 0.98 & $5515.3 \pm 69.7$ & 1.26 & $5557.2 \pm 58.9$ & 1.06 \\
\hline 1875 & $8296.0 \pm 27.7$ & 0.57 & $8257.4 \pm 39.0$ & 0.45 & $8243.6 \pm 35.5$ & 0.41 \\
\hline \multicolumn{7}{|c|}{20 - $\beta$-hydroxyecdysone } \\
\hline 750 & $3512.4 \pm 34.4$ & 0.98 & $3486.3 \pm 26.8$ & 0.77 & $3549.9 \pm 21.8$ & 0.61 \\
\hline 1500 & $6376.6 \pm 16.1$ & 0.25 & $6332.2 \pm 27.6$ & 0.44 & $6381.1 \pm 27.4$ & 0.43 \\
\hline 2250 & $9476.8 \pm 13.44$ & 0.14 & $9480.1 \pm 27$ & 0.28 & $9454.4 \pm 6.7$ & 0.18 \\
\hline \multicolumn{7}{|l|}{ Cordifolioside A } \\
\hline 750 & $2121.0 \pm 5.2$ & 0.24 & $2213.7 \pm 10.5$ & 0.47 & $2213.5 \pm 8.2$ & 0.37 \\
\hline 1500 & $3479.3 \pm 9.3$ & 0.27 & $3444.7 \pm 4.1$ & 0.12 & $3465.0 \pm 4.2$ & 0.12 \\
\hline 2250 & $5208.4 \pm 9.3$ & 0.18 & $5208.5 \pm 5.3$ & 0.10 & $5226.3 \pm 4.2$ & 0.08 \\
\hline
\end{tabular}

${ }^{\mathrm{a}}$ Mean of five replicates 
Table 3 Recovery studies for the determination of cordifolioside A, 20 - $\beta$-hydroxyecdysone, and columbin by HPTLC-DS method

\begin{tabular}{|c|c|c|c|c|c|}
\hline $\begin{array}{l}\text { Percent of ana- } \\
\text { lyte spiked }\end{array}$ & $\begin{array}{l}\text { Total amount in sam- } \\
\text { ple after spiking }\end{array}$ & Total amount found & $\%$ Recovery $^{\mathrm{a}}$ & SD & $\% R S D$ \\
\hline \multicolumn{6}{|l|}{ Cordifolioside A } \\
\hline \multirow[t]{3}{*}{80} & 1350 & 1348.91 & 99.92 & 0.39 & 0.39 \\
\hline & & 1339.72 & 99.24 & & \\
\hline & & 1340.09 & 99.27 & & \\
\hline \multirow[t]{3}{*}{100} & 1500 & 1500.32 & 100.02 & 0.77 & 0.76 \\
\hline & & 1512.84 & 100.86 & & \\
\hline & & 1523.36 & 101.56 & & \\
\hline \multirow[t]{3}{*}{120} & 1650 & 1622.74 & 98.35 & 0.10 & 0.10 \\
\hline & & 1620.31 & 98.20 & & \\
\hline & & 1619.54 & 98.15 & & \\
\hline \multicolumn{6}{|c|}{20 - $\beta$-hydroxyecdysone } \\
\hline \multirow[t]{3}{*}{80} & 1350 & 1342.86 & 99.47 & 0.515 & 0.51 \\
\hline & & 1349.87 & 99.99 & & \\
\hline & & 1335.96 & 98.96 & & \\
\hline \multirow[t]{3}{*}{100} & 1500 & 1493.62 & 99.57 & 0.328 & 0.33 \\
\hline & & 1484.74 & 98.98 & & \\
\hline & & 1492.89 & 99.53 & & \\
\hline \multirow[t]{3}{*}{120} & 1650 & 1649.25 & 99.95 & 0.279 & 0.28 \\
\hline & & 1657.03 & 100.43 & & \\
\hline & & 1648.88 & 99.93 & & \\
\hline \multicolumn{6}{|l|}{ Columbin } \\
\hline \multirow[t]{3}{*}{80} & 1350 & 1335.00 & 98.80 & 0.39 & 0.39 \\
\hline & & 1327.13 & 98.22 & & \\
\hline & & 1325.05 & 98.06 & & \\
\hline \multirow[t]{3}{*}{100} & 1500 & 1485.00 & 98.80 & 0.23 & 0.23 \\
\hline & & 1478.52 & 98.37 & & \\
\hline & & 1479.72 & 98.45 & & \\
\hline \multirow[t]{3}{*}{120} & 1650 & 1635.00 & 98.80 & 0.35 & 0.35 \\
\hline & & 1627.13 & 98.32 & & \\
\hline & & 1623.76 & 98.12 & & \\
\hline
\end{tabular}

${ }^{\mathrm{a}}$ Mean of three replicates / three concentration levels

\subsection{Characterization of compounds by HPTLC-MS/MS}

To confirm selected markers compounds (1-3) from $T$. cordifolia, TLC-MS interface combined with indirect profiling of LC-ESI-MS/MS analysis has been used. Compound (1) was eluted at Rt $4.71 \mathrm{~min}$ at the wavelength of $221 \mathrm{~nm}$ and was obtained in its sodium ion adduct $[\mathrm{M}+\mathrm{Na}]^{+}$at $m / z=527.0$ and potassium ion adduct $[\mathrm{M}+\mathrm{K}]^{+}$at $m / z=541.1$. Two prominent fragment ions of compound (1) were observed at $m / z=312.4[\mathrm{M}+\mathrm{Na}-$ $\left.\mathrm{C}_{11} \mathrm{H}_{15} \mathrm{O}_{2}\right]^{+}$with the loss of two sugar moieties, and at $\mathrm{m} / \mathrm{z}=333.16\left[\mathrm{M}-\mathrm{C}_{6} \mathrm{H}_{15} \mathrm{O}_{9}-2 \mathrm{OH}^{-}\right]^{+}$with the loss of one sugar moiety and two - $\mathrm{OH}$ atoms from the parent molecule. The fragments collectively confirmed compound (1) using ESI-MS. Compound (2) was later eluted at the Rt
$11.36 \mathrm{~min}$, at the maximum wavelength of $247 \mathrm{~nm}$. The compound was observed in positive ion mode with the prominent molecular ion peak at $[\mathrm{M}+\mathrm{H}]^{+}$at $m / z=481.30$ followed by the formation of its two adducts, namely, sodium adduct $[\mathrm{M}+\mathrm{Na}]^{+}$at $m / z=503.31$ and potassium adduct $[\mathrm{M}+\mathrm{K}]^{+}$at $m / z=519.23$. Two major fragment ions of compound (2) were observed at $[\mathrm{M}-\mathrm{OH}]^{+}$ at $m / z=464.31$ (loss of an $-\mathrm{OH}$ ion), and another fragment was observed at $m / z=426.13$ (with the loss of $\left[\mathrm{M}-\mathrm{CH}_{2} \mathrm{OH}\right]^{-}$ion). Subsequently, the mass spectra of compound (3) showed a protonated molecular ion peak $[\mathrm{M}+\mathrm{H}]^{+}$at $m / z=359$ followed by two prominent fragment ions observed as the deprotonated ions at $m / z=340$ with loss of water molecule $\left[\mathrm{M}-\mathrm{H}_{2} \mathrm{O}-\mathrm{H}\right]^{+}$and $m / z=312$ with the deprotonated ion and loss of two carbonyl ions [M-H$\left.\mathrm{CO}_{2}\right]^{+}$at positive ESI mode. Compound (3) was obtained at Rt $24.49 \mathrm{~min}$ at $210 \mathrm{~nm}$ (Table 5, Fig. 7 and Fig. S5). 

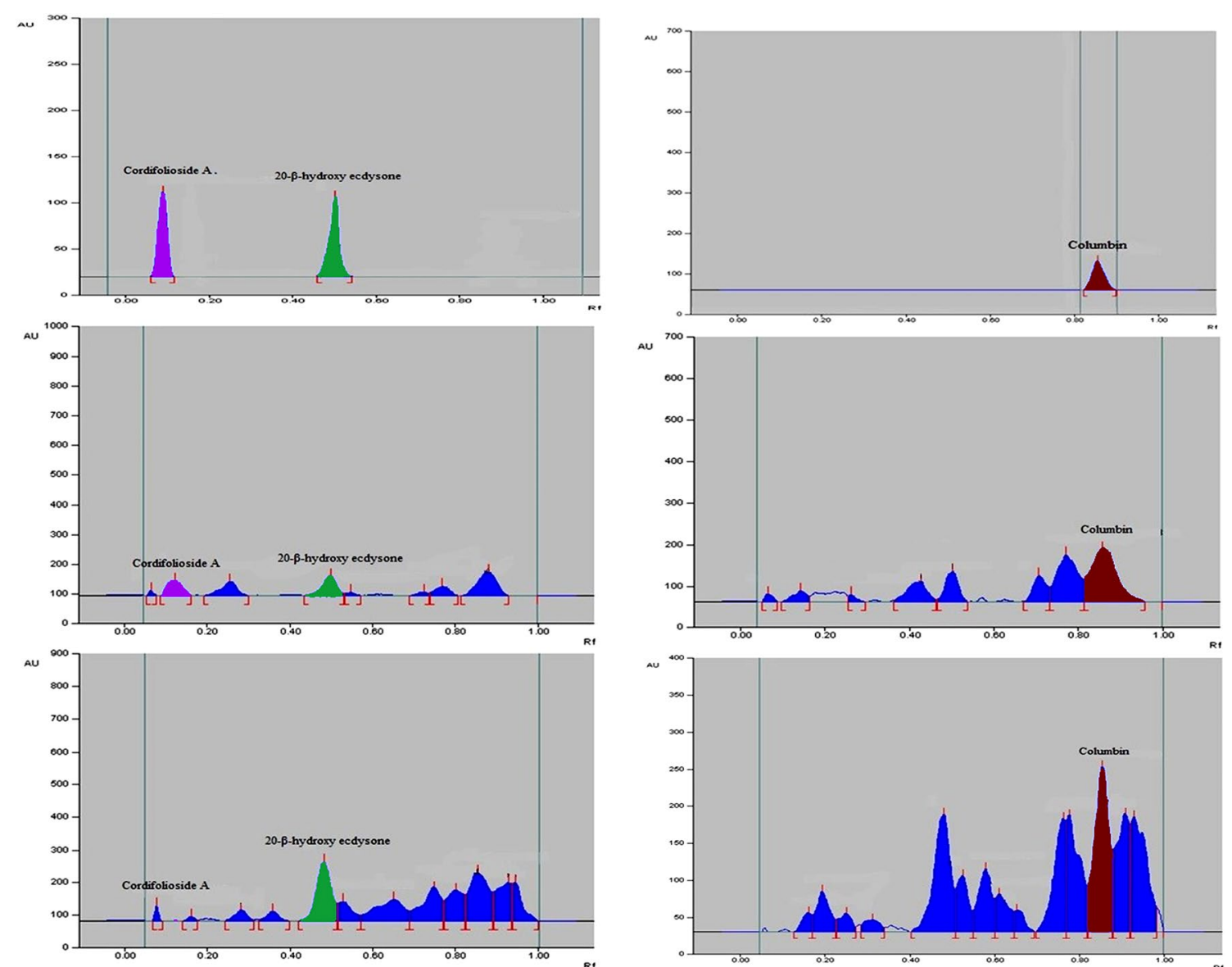

Fig. 5 Developed HPTLC densitograms of markers with hydroalcoholic and aqueous extracts. A at $254 \mathrm{~nm}$. B After derivatization at $600 \mathrm{~nm}$
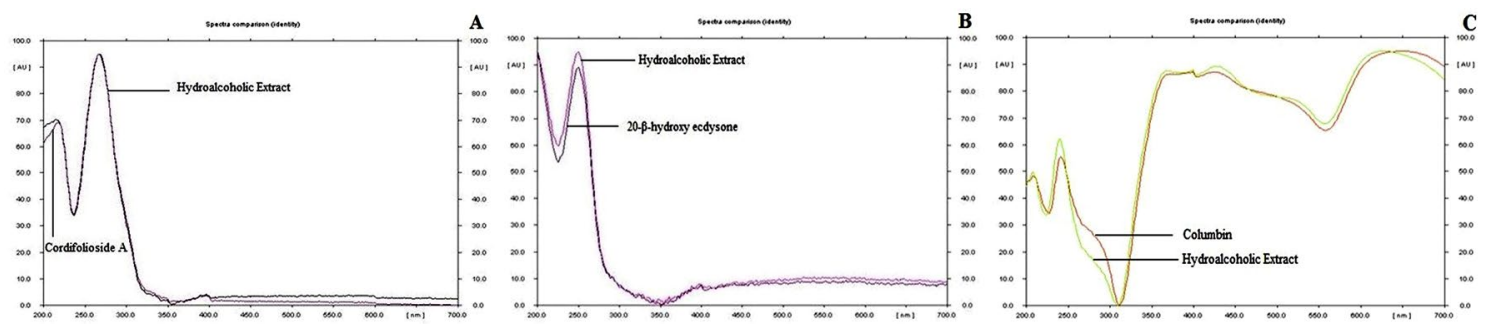

Fig. 6 Densitometric UV spectra of standard markers with hydroalcoholic extract. A Cordifolioside A before derivatization. B 20- $\beta$-hydroxyecdysone before derivatization. C Columbin after derivatization with anisaldehyde-sulfuric acid 
Table 4 Quantification of cordifolioside A, 20- $\beta$-hydroxyecdysone, and columbin in aqueous extract and hydroalcoholic extract by the validated HPTLC-DS method

\begin{tabular}{llll}
\hline Extract & $\begin{array}{l}\text { Mean percent of cordifolioside } \mathrm{A}^{\mathrm{a}} \\
(\% \mathrm{mg} / \mathrm{mg}) \pm \% R S D\end{array}$ & $\begin{array}{l}\text { Mean percent of 20- } \beta \text {-hydroxyecdysone } \\
(\% \mathrm{mg} / \mathrm{mg}) \pm \% R S D\end{array}$ & $\begin{array}{l}\text { Mean percent of } \\
\text { columbin } \\
\mathrm{mg}) \pm \% R S D\end{array}$ \\
\hline Aqueous extract & $0.017 \pm 0.66$ & $0.499 \pm 0.75$ & $0.284 \pm 0.80$ \\
Hydroalcoholic extract & $0.134 \pm 0.52$ & $0.845 \pm 0.43$ & $0.196 \pm 0.55$ \\
\hline
\end{tabular}

${ }^{a}$ Mean of three replicates

Table 5 ESI-MS/MS

fragmentation of markers of $T$. cordifolia

\begin{tabular}{llll}
\hline Marker name & Molecular weight & Fragmentation ions $\left(\mathrm{MS}^{\mathrm{n}}\right)$ & Precursor ion adducts \\
\hline Cordifolioside A & 527.00 & $211.20,246.20$ & $527.00[\mathrm{M}+\mathrm{Na}]^{+} 541.20[\mathrm{M}+\mathrm{K}]^{+}$ \\
$20-\beta$-hydroxyecdysone & 481.05 & $427.10,445.40,463.50$ & $504.50[\mathrm{M}+\mathrm{Na}]^{+} 579.30[\mathrm{M}+\mathrm{K}]^{+}$ \\
Columbin & 359.00 & $341.00,313.10$ & - \\
\hline
\end{tabular}
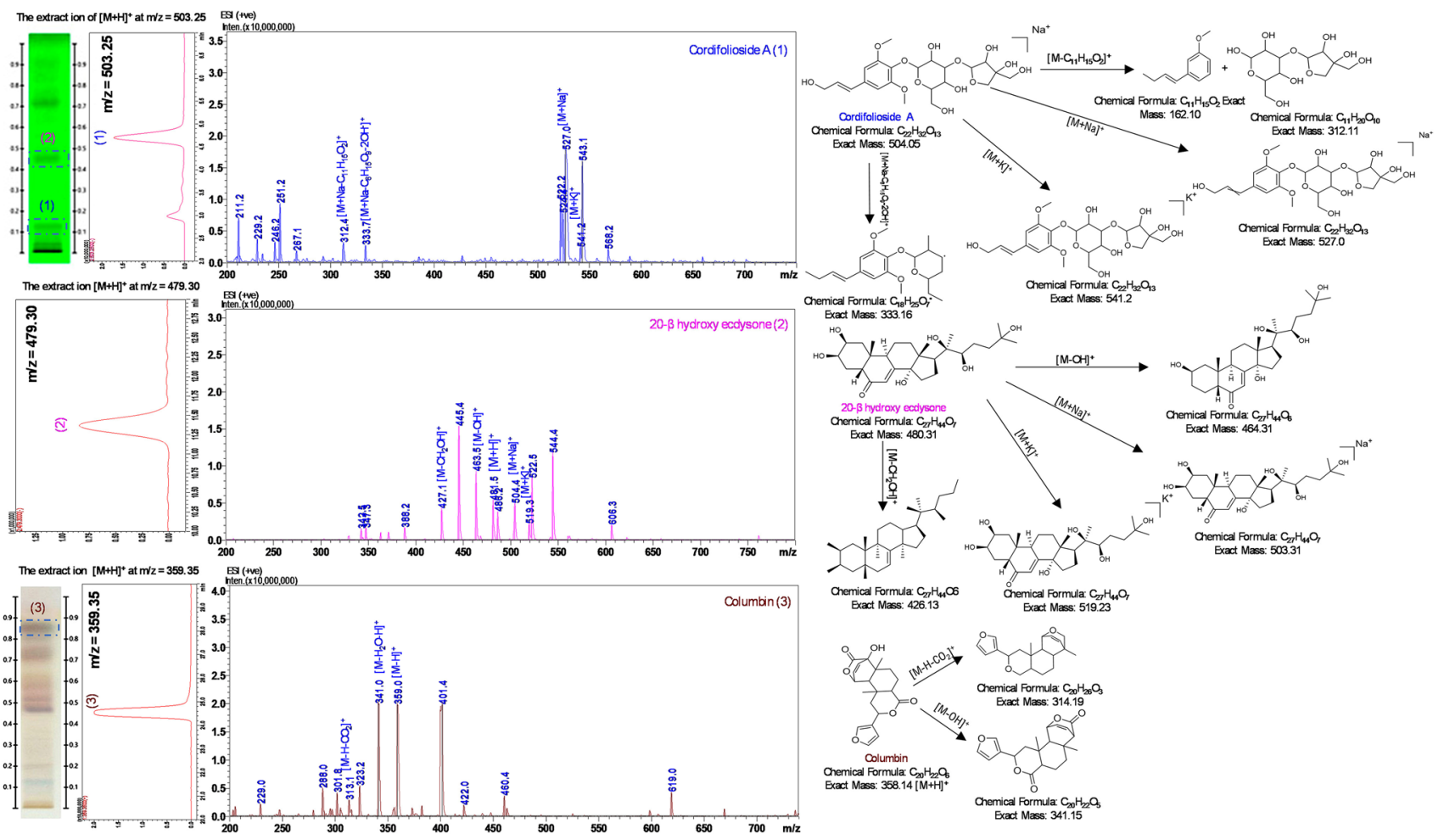

Fig. 7 HPTLC-ESI-MS/MS chromatogram of hydroalcoholic extracts of $T$. cordifolia stem identifying cordifolioside A, 20- $\beta$-hydroxyecdysone ( $254 \mathrm{~nm}$ before derivatization) and columbin (visible light after derivatization) with its mass fragmentation pattern

\section{Conclusion}

The TLC-MS interface technique was used for the separation of cordifolioside A, 20- $\beta$-hydroxyecdysone, and columbin from $T$. cordifolia extract. HPTLC-MS/MS analysis confirmed the presence of compounds (1-3) in stem extracts (hydroalcoholic and aqueous) of $T$. cordifolia. The developed and validated HPTLC method for estimation of three markers may be useful for the quality control and standardization of these extracts and its further role in traditional medicines and nutraceuticals.

Supplementary Information The online version contains supplementary material available at https://doi.org/10.1007/s00764-021-00115-7.

Acknowledgements The authors express their gratitude to Dr Amit Mirgal and Mr Ganesh Saste (Pharmanza Herbal Pvt. Ltd.; Anand, Gujarat, India) for their assistance in this project for providing authentication of plant and extract of $T$. cordifolia. The authors are also grateful 
to sophisticated analytical instrument facilities, Gujarat Technological University, Ahmedabad, India, for providing the facility of TLC-MS interface.

\section{References}

1. Brown PN, Chan M, Betz JM, Shahid M, Cannon S, Palissery J, Puglisi MP (2020) Chapter 2: regulation of nutraceuticals in Canada and the United States. In: Spagnuolo PA (ed.) Nutraceuticals and human health: the food-to-supplement paradigm. Royal Society of Chemistry, London, pp. 22-40. https://doi.org/10.1039/ 9781839160578-00007

2. Tilburt JC, Kaptchuk TJ (2008) Herbal medicine research and global health: an ethical analysis. Bull World Health Organ 86:594-599. https://doi.org/10.2471/BLT.07.042820

3. Tripathi C, Girme A, Champaneri S, Patel RJ, Hingorani L (2020) Nutraceutical regulations: an opportunity in ASEAN countries. Nutrition 74:110729. https://doi.org/10.1016/j.nut.2020.110729

4. Sen S, Chakraborty R (2017) Revival, modernization and integration of Indian traditional herbal medicine in clinical practice: Importance, challenges and future. J Tradit Complement Med 7:234-244. https://doi.org/10.1016/j.jtcme.2016.05.006

5. Girme A, Saste G, Pawar S, Balasubramanian AK, Musande K, Darji B, Satti NK, Verma MK, Anand R, Singh R, Vishwakarma RA, Hingorani L (2020) Investigating 11 withanosides and withanolides by UHPLC-PDA and mass fragmentation studies from ashwagandha (withaniasomnifera). ACS Omega 5:27933-27943. https://doi.org/10.1021/acsomega.0c03266

6. Hanuman JB, Bhatt RK, Sabata B (1988) A clerodane furano-diterpene from Tinospora cordifolia. J Nat Prod 51:197-120. https:// doi.org/10.1021/np50056a001

7. Sivarajan VV, Balachandran I (1999) Ayurvedic drugs and their plant sources. CBS Publishers \& Distributors Pvt Ltd, New Delhi, pp 527-544

8. Singh SS, Pandey SC, Srivastava S, Gupta VS, Patro B (2003) Chemistry and medicinal properties of Tinospora cordifolia (Guduchi). Indian J Pharmacol 35:83-91

9. Sivakumar V, Dhana Rajan MS (2011) Hypoglycemic and antioxidant activity of Tinospora cordifolia in experimental diabetes. Int J Pharm Sci Res 2(3):608-613. https://doi.org/10.13040/IJPSR. 0975-8232

10. Hingorani L, Thawani V, inventor; Verdure Sciences Inc, assignee. Composition containing Tinospora cordifolia and process for obtaining same. U.S. Patent No. 20060045923A1. January 19, 2007.

11. Badar VA, Thawani VR, Wakode PT, Shrivastava MP, Gharpure KJ, Hingorani LL, Khiyani RM (2005) Efficacy of Tinospora cordifolia in allergic rhinitis. J Ethnopharmacol 96(3):445-449. https://doi.org/10.1016/j.jep.2004.09.034

12. Gangrade G, Thawani V, Sagdeo V, Ughade S (2006) Efficacy of Tinospora cordifolia in Thermal Burn patients. Indian Med Gaz 140(1):38-43

13. Kalikar MV, Thawani VR, Varadpande UK, Sontakke SD, Singh RP, Khiyani RK (2008) Immunomodulatory effect of Tinospora cordifolia extract in human immuno-deficiency virus positive patients. Indian J Pharmacol 40(3):107-110. https://doi.org/10. 4103/0253-7613.42302

14. Council of Scientific \& Industrial Research (1982) Publication \& Information Directorate, vol 10. New Delhi, p 252

15. Qudrat-I-Khuda M, Khaleque A, Bashir A, Roufk MDA, Ray N (1966) Tinospora cordifolia-isolation of tinosporon, tinosporic acid and tinosporol from fresh creeper. Sci Res 3:9-12
16. Kiem PV, Minh CV, Dat NT, Kinh LV (2010) Aporphine alkaloids, clerodane diterpenes, and other constituents from Tinospora cordifolia. Fitoterapia 81(6):485-489. https://doi.org/10.1016/j. fitote.2010.01.005

17. Dinan L (2001) Phytoecdysteroids: biological aspects. Phytochemistry 57(3):325-339. https://doi.org/10.1016/S00319422(01)00078-4

18. Dinan L (2009) The Karlson lecture. Phytoecdysteroids: what use are they? Arch Insect Biochem Physiol 72(3):126-141. DOI:https://doi.org/10.1002/arch.20334

19. Lafont R, Dinan L (2003) Practical uses for ecdysteroids in mammals including humans: an update. J Insect Sci 3:7. https://doi.org/ 10.1093/jis/3.1.7

20. Lafont R, Dinan L (2006) Effects and applications of anthropod steroid hormones (ecdysteroids) in mammals. J Endocrinol 191(1):1-8. https://doi.org/10.1677//joe.1.06900

21. Maurya R, Wazir V, Kapil A, Kapil RS (1996) Cordifoliosides $\mathrm{A}$ and $\mathrm{B}$, two new phenylpropene disaccharides from Tinospora cordifolia possessing immunostimulant activity. Nat Prod Lett 8(1):7-10. https://doi.org/10.1080/10575639608043231

22. Patel A, Bigoniya P, Singh CS, Patel NS (2013) Radioprotective and cytoprotective activity of Tinospora cordifolia stem enriched extract containing cordifolioside-A. Indian J Pharmacol 45(3):237. https://doi.org/10.4103/0253-7613.111919

23. Sharma U, Bala M, Kumar N, Singh B, Munshi RK, Bhalerao S (2012) Immunomodulatory active compounds from Tinospora cordifolia. J Ethnopharmacol 141(3):918-926. https://doi.org/10. 1016/j.jep.2012.03.027

24. Lital M, Camelo S, Veillet S, Lafont R, Dilda PJ (2021) Developing new drugs that activate the protective arm of the reninangiotensin system as a potential treatment for respiratory failure in COVID-19 patients. Drug Discov Today 26(5):1311-1318. https://doi.org/10.1016/j.drudis.2021.02.010

25. Ahmad SM, Hoot SB, Qazi PH, Verma V (2009) Phylogenetic patterns and genetic diversity of Indian Tinospora species based on chloroplast sequence data and cytochrome P450 polymorphisms. Plant Syst Evol 281(1-4):87-96. https://doi.org/10.1007/ s00606-009-0189-1

26. Singh D, Chaudhari PK (2017) Chemistry and pharmacology of Tinospora cordifolia. Natu Prod Commun 2(12):299-308

27. Chowdhury P (2020) Ayurveda botanicals in COVID-19 management: an in silico multi-target approach. J Biomol Struct Dyn 2020:1-18. https://doi.org/10.1371/journal.pone.0248479

28. Shree P, Mishra P, Selvaraj C (2020) Targeting COVID-19 (SARS-CoV-2) main protease through active phytochemicals of ayurvedic medicinal plants Withania somnifera (Ashwagandha), Tinospora cordifolia (Giloy) and Ocimum sanctum (Tulsi). A molecular docking study. J Biomol Struct Dyn 2020:1-14. https://doi.org/10.3389/fphar.2021.635510

29. Patwardhan B, Chavan-Gautam P, Gautam M, Tillu G, Chopra A, Gairola S, Jadhav S (2020) Ayurveda rasayana in prophylaxis of COVID-19. Curr Sci 118:1158-1160

30. Tine Y, Renucci F, Costa J, Wélé A, Paolini J (2017) A Method for LC-MS/MS Profiling of Coumarins in Zanthoxylum zanthoxyloides (Lam.) B. Zepernich and Timler Extracts and Essential Oils. Molecules 22(1):174. https://doi.org/10.3390/molecules22010174

31. Zhao L, Huang C, Shan Z, Xiang B, Mei L (2005) Fingerprint analysis of Psoralea corylifolia L. by HPLC and LC-MS. J Chromatogr B 821(1):67-74. https://doi.org/10.1016/j.jchromb.2005. 04.008

32. Ahmed SM, Manhas LR, Verma V, Khajuria RK (2006) Quantitative determination of four constituents of tinosporasps by a reversed-phase HPLC-UV-DAD method. Broad-based studies revealing variation in content of four secondary metabolites in the plant from different eco-geographical regions of India. 
J Chromatogr Sci. 44(8):504-509. https://doi.org/10.1093/chrom sci/44.8.504

33. Puratchimani V, Jha S (2007) HPTLC standardization of Tinospora cordifolia using Tinosporaside. Indian J Pharm Sci 69(4):578-581

34. Parveen A, Adams JS, Raman V, Budel JM, Zhao J, Babu GNM, Ali Z, Khan IA (2020) Comparative morpho-anatomical and HPTLC profiling of Tinospora species and dietary supplements. Planta Med 86(7):470-481. https://doi.org/10.1055/a-1120-3711

35. Haque A, Jantan I, Bukhari SNA (2017) Tinospora species: an overview of their modulating effects on the immune system. $\mathbf{J}$ Ethnopharmacol 207:67-85. https://doi.org/10.1016/j.jep.2017. 06.013

36. Srinivasan GV, Unikrishnan KP, Rema Shree AB, Balachandran I (2008) HPLC Estimation of berberine in Tinospora cordifolia and Tinospora sinensis. Indian J Pharm Sci 70(1):96-99. https:// doi.org/10.4103/0250-474X.40341

37. Sivakumar V, Dhana Rajan MS (2010) Antioxidant effect of Tinospora cordifolia extract in alloxan-induced diabetic rats. Indian J Pharm Sci Res 72(6):795-798

38. Parveen A, Wang Y-H, Fantoukh O, Alhusban M, Raman V, Ali Z, Khan IA (2019) Development of a chemical fingerprint as a tool to distinguish closely related Tinospora species and quantitation of marker compounds. J Pharm Biomed Anal 178:112894. https:// doi.org/10.1016/j.jpba.2019.112894

39. Balkrishna A, Kumar MH, Gupta AK (2016) Comparative analysis of HPTLC, secondary metabolites and antioxidant activities of Tinospora cordifolia stem powders. Indian J Pharm Sci Res 7(10):4263-4271. https://doi.org/10.13040/IJPSR.0975-8232

40. Sen S, Chakraborty R, De B (2011) Challenges and opportunities in the advancement of herbal medicine: India's position and role in a global context. J Herb Med 1(3-4):67-75. https://doi.org/10. 1016/j.hermed.2011.11.001

41. Sahoo N, Manchikanti P, Dey S (2010) Herbal drugs: standards and regulation. Fitoterapia 81(6):462-471. https://doi.org/10. 1016/j.fitote.2010.02.001

42. Parasuraman S, Thing GS, Dhanaraj SA (2014) Polyherbal formulation: Concept of Ayurveda. Pharmacogn Rev 8(16):73-80. https://doi.org/10.4103/0973-7847.134229
43. Kirtikar KR, Basu BD (1933) Indian medicinal plants, 2nd edn, vol 1. Lalit Mohan Basu, Allahabad, pp 77-78

44. Wet DH, Struwig M, Van Wyk BE (2016) Taxonomic notes on the genera Tiliacora and Tinospora (Menispermaceae) in southern Africa. S Afr J Bot 103:283-294. https://doi.org/10.1016/j.sajb. 2015.05.030

45. Singh D, Chaudhuri PK (2017) Chemistry and pharmacology of Tinospora cordifolia. Nat Prod Commun 12(2):299-308. https:// doi.org/10.1177/1934578X1701200240

46. Hungerford NL, Sands DPA, Kitching W (1998) Isolation and Structure of some constituents of the Australian Medicinal Plant Tinospora smilacina ('Snakevine'). Aust J Chem 51(12):11031112. https://doi.org/10.1071/c98034

47. Pathak AK, Agarwal PK, Jain DC (1995) NMR studies of a 20- $\beta$-hydroxy ecdysone, a steroid, isolated from Tinospora cordifolia. Indian J Chem 34(7):674-676

48. ICH Harmonized Tripartite Guideline, Validation of Analytical Procedures: Text and Methodology Q2 (R1) (2005) International Conference on Harmonization, Geneva

49. Gohel K, Patel K, Shah P, Hingorani L, Gandhi T (2018) BoxBehnken design-assisted optimization for simultaneous estimation of quercetin, kaempferol, and keto- $\beta$-boswellic acid by high-performance thin-layer chromatography method. J Planar Chromatogr-Mod TLC 31:318-326. https://doi.org/10.1556/1006.2018. 31.4.7

50. Heinig K, Wirz T, Gajate-Perez A (2010) Sensitive determination of a drug candidate in dried blood spots using a TLC-MS interface integrated into a column-switching LC-MS/MS system. Bioanalysis 2(11):1873-1882. https://doi.org/10.4155/bio.10.133

51. Khan A, Zahiruddin S, Ibrahim M, Basist P, Gaurav, Parveen R, Umar S, Ahmed S (2021) Thin layer chromatography-mass spectrometry bioautographic identification of free radical scavenging compounds and metabolomic profile of Carica papaya linn fruit and seeds using high-performance thin-layer chromatography, gas chromatography-mass spectrometry and ultra-performance liquid chromatography-mass spectrometry. Phcog Mag 17(5):21-28. 